\title{
Diabetology: A New Online Diabetes Journal. What Role Can It Play in a Crowded Field?
}

\author{
Peter Clifton ${ }^{1,2}$ (D) \\ 1 Founding Editor-in-Chief of Diabetology, Nutrition and Activity (ARENA)/Clinical and Health Sciences, \\ University of South Australia, Adelaide SA 5001, Australia; Peter.Clifton@unisa.edu.au \\ 2 Royal Adelaide Hospital, Port Rd, Adelaide SA 5000, Australia
}

Received: 14 October 2020; Accepted: 21 October 2020; Published: 21 October 2020

As a general physician with an interest in endocrinology, more than half of my patients have type 2 diabetes invariably accompanied by obesity, and in almost all cases at least one complication of diabetes. Most of these patients are trying hard to take control of their lives, and get on top of type 2 diabetes, but some have given up and feel powerless to change the disease. Most clinicians who see people with diabetes, whether specialists, general physicians or general practitioners, need evidence that they can apply to the patient in front of them in the absence of all the support available for clinical trials in research centers.

One area this journal could have a particular focus on is behavioral modification and support in diabetes. There are few open access journals that address this area, which is still important, despite much improved medication. Many patients are keen to improve their lifestyle and reduce or eliminate medication.

I would like to see this journal also have a particular focus on pragmatic trials conducted by individuals or groups of practitioners with a common goal of translating the outcomes from controlled trials into practical advice for individual patients, whether this is psychological support, nutritional advice, drug therapy or exercise. These reports might be summaries of the practitioners' experience with individual patients, and need not be randomized or controlled, nor necessarily large enough to be statistically significant. These types of studies would struggle to get published elsewhere, but provide useful advice for the clinician on the likelihood of the success or failure of a particular intervention in a routine clinical setting. In addition, pragmatic trials with no or limited dietetic input and normal clinician contact every two to three months would be welcome.

One good example of the gap between clinical trials and clinical practice is a low carbohydrate diet for both type 1 and type 2 diabetes. Recent meta-analyses would suggest there is a small benefit to be derived for type 2 diabetes from glycemic control, which does not persist beyond 12 months [1,2], but there is a wide range of early responses in $\mathrm{HbA} 1 \mathrm{c}$ from $-0.9 \%$ to $+0.2 \%$ at three to six months [2]. At 12 months, all trials are similar, with no heterogeneity and a clear null effect. This result would suggest there is no point in trying to reduce carbohydrate intake for the patient or the doctor, but of course hidden within these null results is a small number of individuals, perhaps only $10-20 \%$ of the group, who have responded well and maintained their responses up to 12 months or beyond. We need to know what the characteristics of these patients were, what strategies they used to reduce their carbohydrate intake, and what foods they could reduce long-term. Most of the trials in the meta-analyses were isocaloric, and dietary intake was closely monitored and recorded by dietitians, but none of this applies in clinical practice.

We will commission reviews to finely dissect clinical trials to discern if some of these questions can be answered using the currently available clinical trial data. 


\section{References}

1. Sainsbury, E.; Kizirian, N.V.; Partridge, S.R.; Gill, T.; Colagiuri, S.; Gibson, A.A. Effect of dietary carbohydrate restriction on glycemic control in adults with diabetes: A systematic review and meta-analysis. Diabetes Res. Clin. Pr. 2018, 139, 239-252. [CrossRef] [PubMed]

2. Snorgaard, O.; Poulsen, G.M.; Andersen, H.K.; Astrup, A. Systematic review and meta-analysis of dietary carbohydrate restriction in patients with type 2 diabetes. BMJ Open Diabetes Res. Care 2017, 5, e000354. [CrossRef] [PubMed]

Publisher's Note: MDPI stays neutral with regard to jurisdictional claims in published maps and institutional affiliations.

(C) 2020 by the author. Licensee MDPI, Basel, Switzerland. This article is an open access article distributed under the terms and conditions of the Creative Commons Attribution (CC BY) license (http://creativecommons.org/licenses/by/4.0/). 